\title{
Comparison between Stereo Optical Strain Measurements and Finite Element Results in Stress Concentration Zones
}

\author{
Bruno GLASER, Jožef PREDAN, Dražan KOZAK, Nenad GUBELJAK
}

\begin{abstract}
Experimental testing and deformation measurements during static loading in areas with high gradients are usually accompanied by uncertainties and inaccuracies of the applied methods. Comparison between different experimentally determined deformations and numerical calculation results of deformations at the determined measured points could be used to determine sensitivities and suitability of the particular measurement method for small deformations and pronounced levels of plastification. The paper presents analysis of combined deformation measurement methods with strain gauges and stereo-optical methods near the fatigue crack on the specimen during tensile loading. The results show that strain gauges are suitable for measurements at smaller deformations as applied for monitoring deformations during fatigue crack propagation. The stereo optical methods are suitable for measurements when significant elastic deformations occur, i.e. near the yield point, during static testing with plastic deformations and material fracture.
\end{abstract}

Keywords: crack propagation; digital image correlation; fatigue; fatigue crack growth rate; finite element method; stereo-optical measurements; strain gauge

\section{INTRODUCTION}

Components and structures exposed to fatigue with elastic dynamic loading respond with elastic strains on the surface of the material [1, 2, 3 and 4]. The mechanical response could be monitored by deformations on the surface with electronic devices dedicated for on-line measurements equipped with appropriate computerized monitoring system for evaluation and analysis. In previous work $[5,6]$ an evaluation of crack depth growth was performed by strain gauge measuring sensors based on surface deformation relaxation phenomena due to crack depth growth. The monitoring of the material under cyclic loading resulted in an experimentally determined calibration curve, which represents deformation on the surface and depth of the semi-elliptical crack [5, 6]. To extend the method of crack growth estimation on the surface of material, additional stereo-optical surface measurements were applied on the other side of the material with a semi-elliptical crack. The aim of these measurements was to determine and compare results of deformations and determine correlation of specimen behaviour under cyclic loading conditions [7].

Generally, the relation between the stress and strain is given by Hooke's law in matrix form for a linear elastic isotropic material as set of equations:

$\left[\begin{array}{c}\varepsilon_{11} \\ \varepsilon_{22} \\ \varepsilon_{33} \\ 2 \varepsilon_{23} \\ 2 \varepsilon_{13} \\ 2 \varepsilon_{12}\end{array}\right]=\left[\begin{array}{c}\varepsilon_{11} \\ \varepsilon_{22} \\ \varepsilon_{33} \\ \gamma_{23} \\ \gamma_{13} \\ \gamma_{12}\end{array}\right]=\frac{1}{E}\left[\begin{array}{cccccc}1 & -v & -v & 0 & 0 & 0 \\ -v & 1 & -v & 0 & 0 & 0 \\ -v & -v & 1 & 0 & 0 & 0 \\ 0 & 0 & 0 & 2+2 v & 0 & 0 \\ 0 & 0 & 0 & 0 & 2+2 v & 0 \\ 0 & 0 & 0 & 0 & 0 & 2+2 v\end{array}\right]\left[\begin{array}{l}\sigma_{11} \\ \sigma_{22} \\ \sigma_{33} \\ \sigma_{23} \\ \sigma_{13} \\ \sigma_{12}\end{array}\right](1)$

where $\varepsilon_{i j}$ is strain, $\gamma_{i j}=2 \varepsilon_{i j}$ is the engineering shear strain, $E$ is Young's modulus, $v$ is Poisson ratio and $\sigma_{i j}$ is stress. The inverse relation may be written as (Eq. (2)):

$$
\left[\begin{array}{c}
\sigma_{11} \\
\sigma_{22} \\
\sigma_{33} \\
\sigma_{23} \\
\sigma_{13} \\
\sigma_{12}
\end{array}\right]=\frac{E}{(1-v)(1-2 v)}\left[\begin{array}{cccccc}
1-v & v & v & 0 & 0 & 0 \\
v & 1-v & v & 0 & 0 & 0 \\
v & v & 1-v & 0 & 0 & 0 \\
0 & 0 & 0 & \frac{1-2 v}{2} & 0 & 0 \\
0 & 0 & 0 & 0 & \frac{1-2 v}{2} & 0 \\
0 & 0 & 0 & 0 & 0 & \frac{1-2 v}{2}
\end{array}\right]\left[\begin{array}{c}
\varepsilon_{11} \\
\varepsilon_{22} \\
\varepsilon_{33} \\
2 \varepsilon_{23} \\
2 \varepsilon_{13} \\
2 \varepsilon_{12}
\end{array}\right]
$$

and in simplified form using Lamé constants:

$$
\left[\begin{array}{c}
\sigma_{11} \\
\sigma_{22} \\
\sigma_{33} \\
\sigma_{23} \\
\sigma_{13} \\
\sigma_{12}
\end{array}\right]=\left[\begin{array}{cccccc}
2 \mu+\lambda & \lambda & \lambda & 0 & 0 & 0 \\
\lambda & 2 \mu+\lambda & v & 0 & 0 & 0 \\
\lambda & \lambda & 2 \mu+\lambda & 0 & 0 & 0 \\
0 & 0 & 0 & \mu & 0 & 0 \\
0 & 0 & 0 & 0 & \mu & 0 \\
0 & 0 & 0 & 0 & 0 & \mu
\end{array}\right]\left[\begin{array}{c}
\varepsilon_{11} \\
\varepsilon_{22} \\
\varepsilon_{33} \\
2 \varepsilon_{23} \\
2 \varepsilon_{13} \\
2 \varepsilon_{12}
\end{array}\right]
$$

Eq. (2) written in vector form becomes Eq. (3):

$\left[\begin{array}{lll}\sigma_{11} & \sigma_{12} & \sigma_{13} \\ \sigma_{12} & \sigma_{22} & \sigma_{23} \\ \sigma_{13} & \sigma_{23} & \sigma_{33}\end{array}\right]=2 \mu\left[\begin{array}{lll}\varepsilon_{11} & \varepsilon_{12} & \varepsilon_{13} \\ \varepsilon_{12} & \varepsilon_{22} & \varepsilon_{23} \\ \varepsilon_{13} & \varepsilon_{23} & \varepsilon_{33}\end{array}\right]+\lambda \boldsymbol{I}\left(\varepsilon_{11}+\varepsilon_{22}+\varepsilon_{33}\right)(3)$

where $\boldsymbol{I}$ is the identity tensor.

For plane stress, with conditions that $\sigma_{31}=\sigma_{13}=$ $\sigma_{32}=\sigma_{23}=\sigma_{33}=0$, Hooke's law can be written as (Eq. (4)):

$\left[\begin{array}{c}\varepsilon_{11} \\ \varepsilon_{22} \\ 2 \varepsilon_{12}\end{array}\right]=\frac{1}{E}\left[\begin{array}{ccc}1 & -v & 0 \\ -v & 1 & 0 \\ 0 & 0 & 2+2 v\end{array}\right]\left[\begin{array}{c}\sigma_{11} \\ \sigma_{22} \\ \sigma_{12}\end{array}\right]$

The simplified form of Hooke's law for tensile onedimensional loading is written as Eq. (5): 
$\varepsilon_{0}=\frac{\sigma}{E}=\frac{F}{A \cdot E}$

where $\varepsilon_{0}$ is strain, $E$ is Young's modulus, $\sigma$ is stress, and $A$ is the surface of applied force $F$.

The important part of reliable crack propagation monitoring is the estimation of the accuracy of the particular method used during testing. This paper presents suitability of two technical approaches with measurement methods applied on the component with a semi-elliptical crack and estimation, when it is appropriate to use them, with regard to the crack size and tensile strength during cyclic tensile loading test. A specific 3D numerical model with the crack was used to compare experimental and numerical results. The comparison was done with actual deformations measured during tensile test with strain gauges and stereo-optical measurements at specific points on the surface of the component.

\section{EXPERIMENTAL TESTING}

The material of the test sample was structural steel grade S690. The tensile properties are determined by standard tensile testing of round tensile specimen cut out of the plate in the rolling direction according to DIN 50125 and ASTM E 646-91 standards. The nominal thickness of the plate was $8 \mathrm{~mm}$. The experimentally obtained results were:

- Young's modulus: $E=202 \mathrm{GPa}$

- Yield strength: $R_{e H}=659 \pm 15 \mathrm{MPa}$

- Ultimate strength: $R_{m}=786 \pm 5 \mathrm{MPa}$

The tensile flat specimen, also cut-out in the rolling direction, with a cross-section of $32 \times 8 \mathrm{~mm}$ was used for test. The semi-elliptical surface crack was generated by fatigue bending loading from the surface short notch with a maximum applied bending stress $\sigma=76.65 \mathrm{MPa}$ and a frequency of $30 \mathrm{~Hz}$ with a Rotech dynamic machine [8]. After fatigue bending testing the crack was identified and measured by ultra sound inspection. Fig. 1 shows the position of the 10 strain-gauges in the row on the surface of specimen, about $1.7 \mathrm{~mm}$ near surface crack. The position of SG 11 in the middle of surface of specimens is also shown in Fig. 1. It is the bulk specimen strain which represents the nominal strain value as the ratio between the applied force and the cross section, according to Eq. 5. The dimensions of 10 strain gauges in row for type HBM, model 1-KY21-2/120 [10] are shown in detail in Fig. 1.

Tensile testing was performed on servo-hydraulic uniaxial testing machine INSTRON 1255 under room temperature $\left(+23{ }^{\circ} \mathrm{C}\right)$ and under displacement control with a constant stroke velocity of approximately $0.9 \mathrm{~mm} / \mathrm{min}$. The testing set-up for stereo-optical and strain-gauge measurement is shown in Fig. 2.a). The loading characteristic is given in Fig. 2.b). For strain determination two methods are used. One method uses strain gauges at the side of the surface crack and the other method uses stereo-optical measurements on the surface of material on the opposite side of the crack. The recorded force vs. displacement diagram is presented in Fig. 2.c).

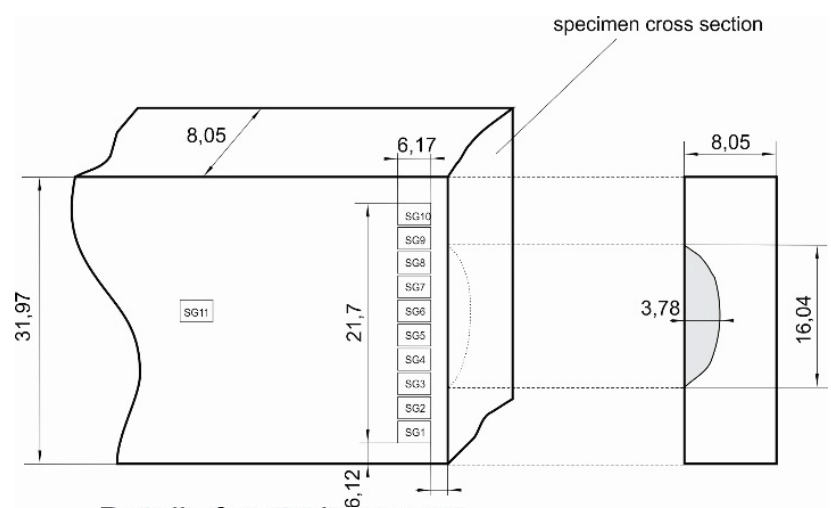

Details for strain gauges

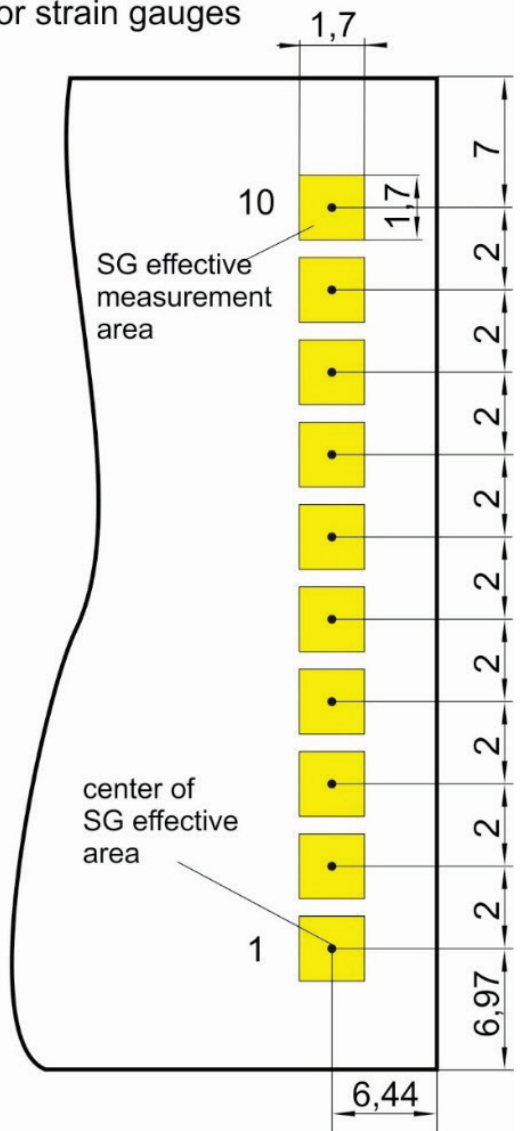

Figure 1 Position of strain-gauges on the surface of the tensile flat specimen, with regard to crack position and the detected crack size

The specimen was monitored simultaneously with the Aramis stereo-optical system and strain gauges. Since the crack was present and grown because of previous cyclic loading, the strain and deformations were distributed near the crack.

The deformations were measured with strain gauges (see Fig. 1) and are shown in Fig. 3. Fig. 3 also shows the same force-time characteristic as in Fig. 2.b), but with different strain magnitude due to different strain gauge locations on the surface.

The ramp loading regime is following the shape and slight shift of deformations due to different locations and surface deformation relaxations near the crack and related strain gauge position. There are slight deviations in the amplitude. The lowest strain amplitude is shown by straingauges in the centre of surface of specimen near the crack, while the highest is shown by strain-gauge 11 , which measured bulk specimen strain, as shown in Fig. 3. 


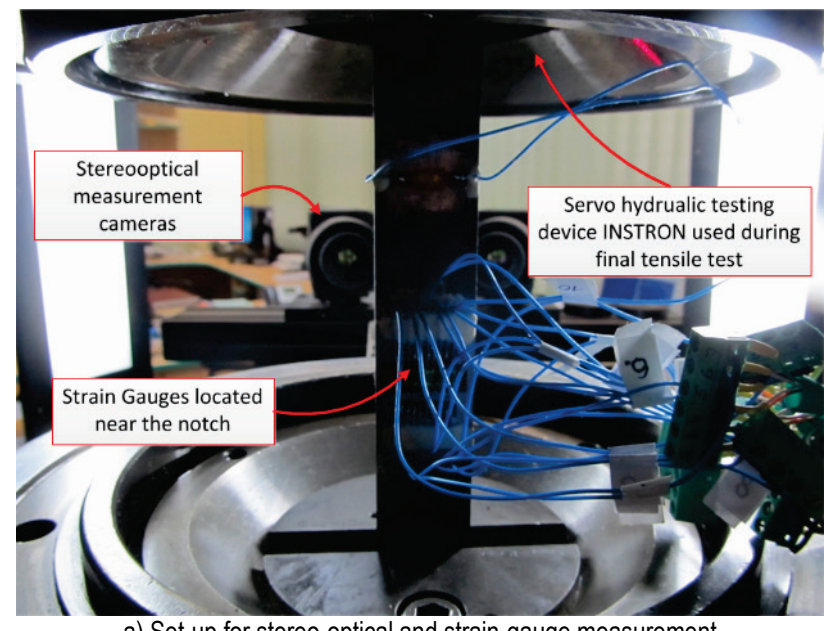

a) Set-up for stereo-optical and strain-gauge measurement

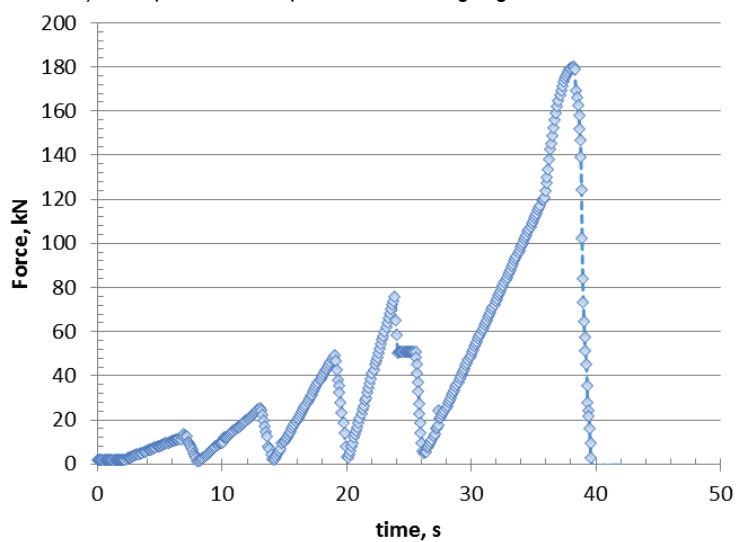

b) Loading force-time characteristic

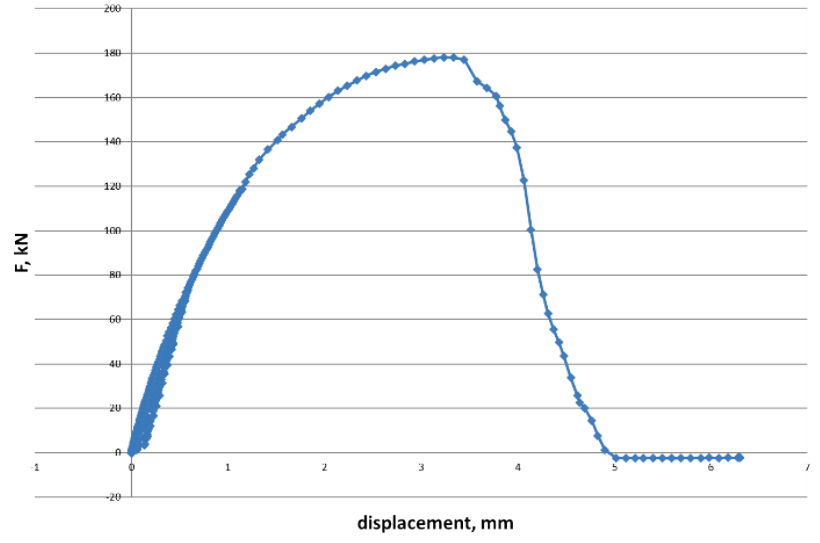

c) Recorded force-displacement curve

Figure 2 Tensile test a) configuration with strain gauges and GOM ARAMIS measurements b) tensile test loading curve and c) recorded force-displacement curve

At the end of tensile test the specimen fractured, as shown in Figs. 4.a) and b). The fractured surface shows a semi-elliptical crack generated from the small notch $(5 \mathrm{~mm}$ width and $1 \mathrm{~mm}$ depth). It is obvious that the crack propagated symmetrically from the left to the right side, in depth to $3.78 \mathrm{~mm}$, and in width up to $16.04 \mathrm{~mm}$. The estimated area of the semi-elliptical crack as measured by Olympus microscope was $50.98 \mathrm{~mm}^{2}$ and the estimated value based on mathematical calculation of the semielliptical area was $47.62 \mathrm{~mm}^{2}$, (Eq. (6)):

$S=\pi \frac{a \cdot b}{2}=47,62 \mathrm{~mm}^{2}$
Therefore, the difference between theoretical and measured crack size is about $7 \%$, which is a reasonable value. The reconstructed crack cross sections geometry was applied for the model for FEM analysis.

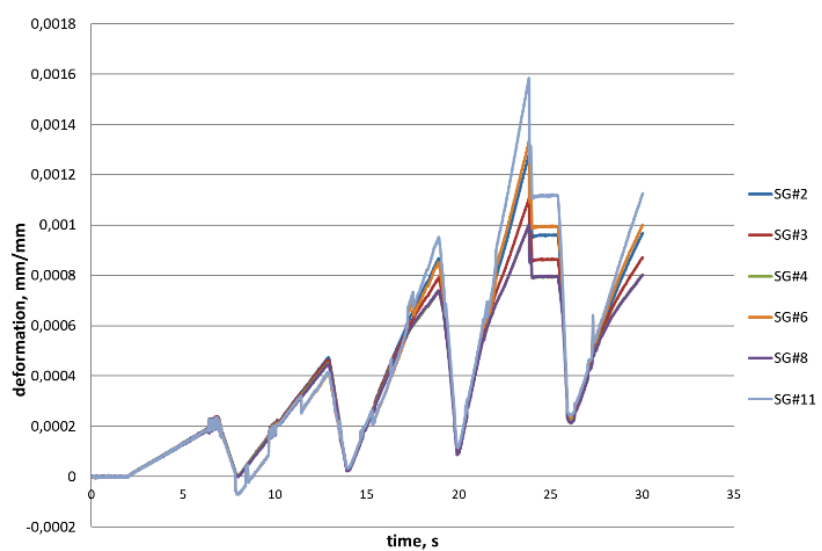

Figure 3 Strain gauges response during tensile test

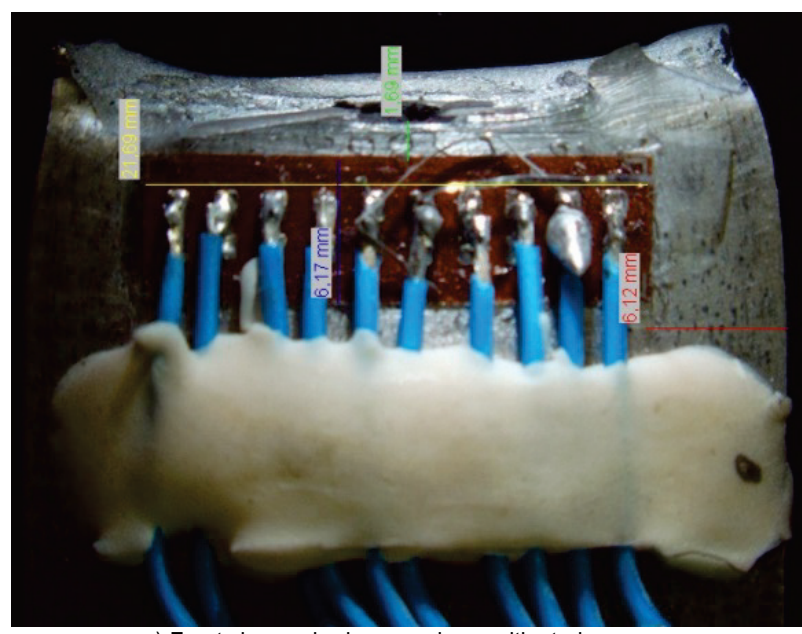

a) Front view on broken specimen with strain gauges

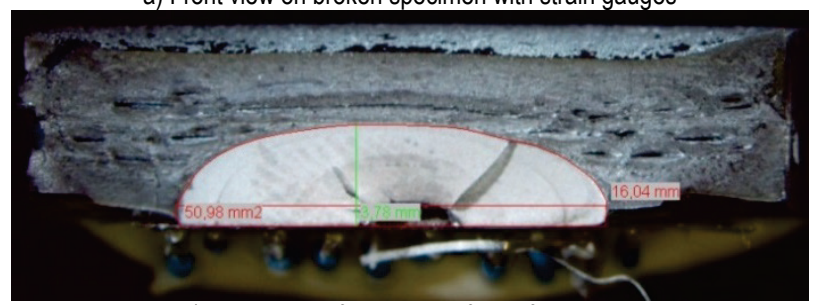

b) Top view on fractured surface of specimen

Figure 4 Fracture surface of tensile specimen after cyclic tensile test with semielliptical surface crack

\section{STEREO-OPTICAL STRAIN MEASUREMENTS}

The stereo optical measurements were performed during tensile test with the GOM Aramis device [9]. The determined rectangular measurement area defined for the specimen is shown in Fig. 5.a).

The observed rectangular area is divided into sections from S0 to S10, which are equidistant from the top to the bottom of the measurement area in the y-direction. The horizontal direction is represented by samples (in our case 123 points). The entire test sequence was measured in time samples (frames) with duration of $250 \mathrm{~ms}$. Every time frame represents the result of strain or deformation at certain time and the correlated loading. The loading was applied as shown in Fig. 2.b). The stereo-optical 
measurements were analysed for all loading regimes. During smaller forces a lot of noise was present. The estimated average deformation noise calculated from the test was $0.7 \times 10^{-3} \mathrm{~mm} / \mathrm{mm}$ (strains). In each point of the section the deformation as engineering strain was calculated. Fig. 5 shows positions of parallel lines in the direction of tensile loading, at different tensile loads. Initial stage without any applied load $F=0$ is shown in Fig. 5.a), while only two stages under applied tensile load $F=120$ $\mathrm{kN}$ and $F=176.3 \mathrm{kN}$ are shown in Figs. 5.b) and 5.c), respectively. It is obvious that the highest strain occurred not below the crack tip, but symmetrically left and right from the crack. Fig. 5.b) shows that maximum strain in the middle is below $1 \%$, which makes difficult to optically recognize exact values of strain when the specimens are loaded by $470 \mathrm{MPa}$ remote stress.

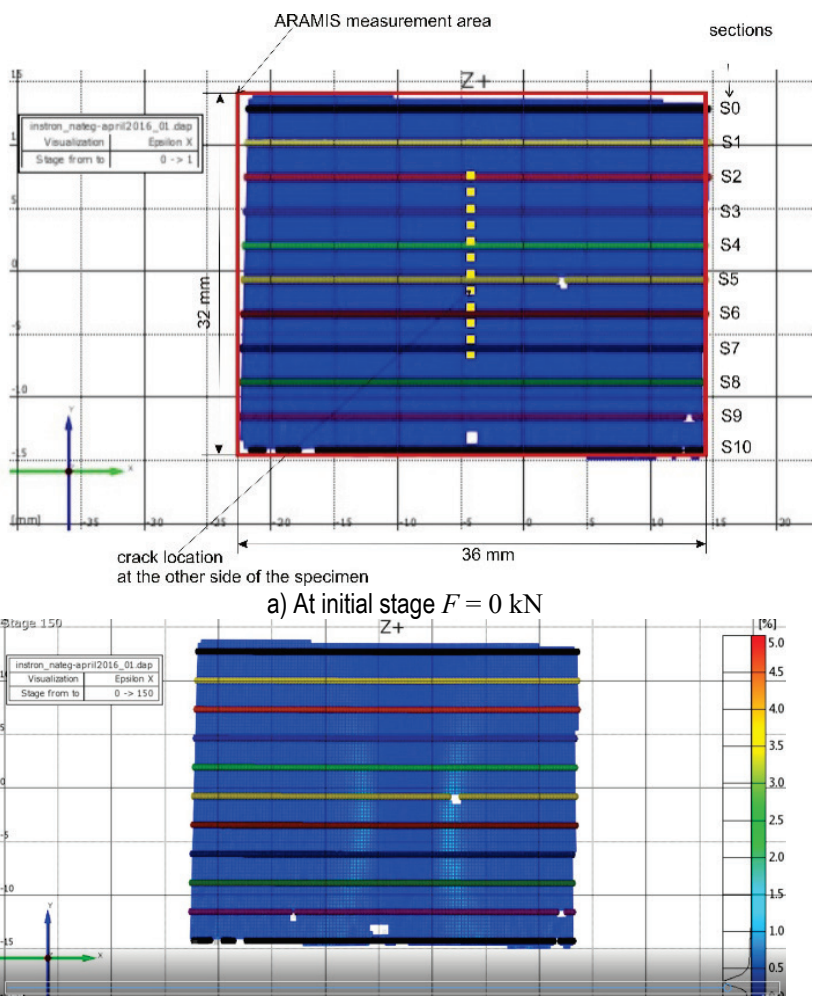

b) At stage $150, F=120 \mathrm{kN}, \sigma=470 \mathrm{MPa}$

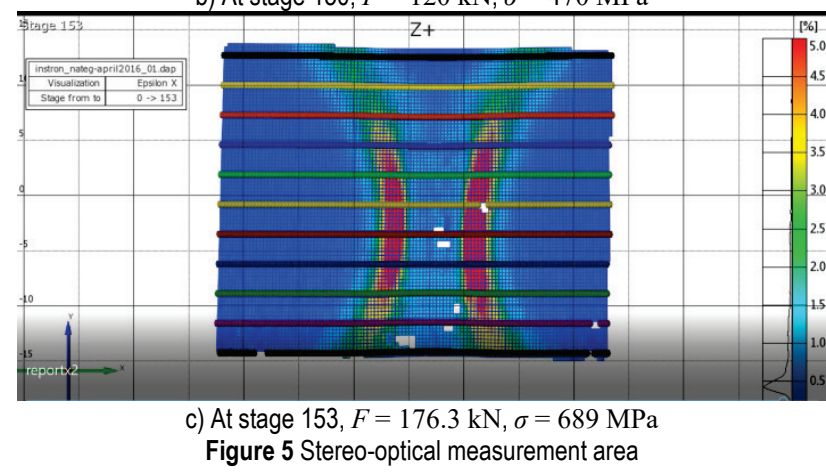

Fig. 5.c) shows that maximum tensile strain locally achieved nearly $5 \%$, with the correspondingly obtained tensile mechanical properties.

The highest peaks are in the middle (section lines 6 and 7) of the specimen. Fig. 5 shows also that the highest strain gradient distribution from the middle of specimen to the upper and lower surface of specimens has an hourglass shape. Therefore, the strain distribution has a 3D shape in the case of a semi-elliptical surface crack. The average nominal deformation apart from the crack is represented by $\varepsilon_{0}$. Near the crack, on the opposite site of the specimen, maximum deformation $\varepsilon_{\max }$ appears at the area at $45^{\circ}$ angle from the crack depth $a$, as shown in Fig. 6. Fig. 7 shows clearly visible maximum peaks measured by the stereooptical method at frame 152 when the specimen was subjected to $F=176.3 \mathrm{kN}$.
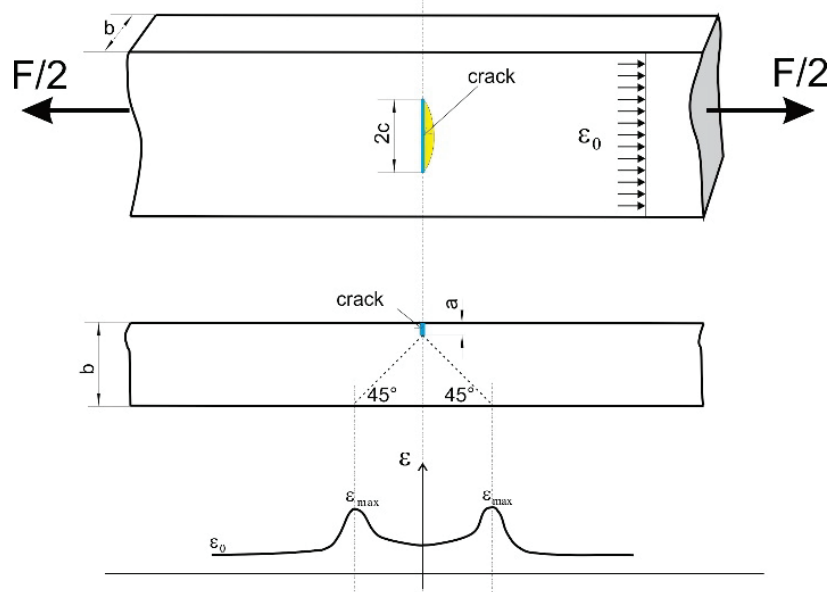

Figure 6 Deformation on the opposing side of the specimen with semi-elliptical crack during tensile test

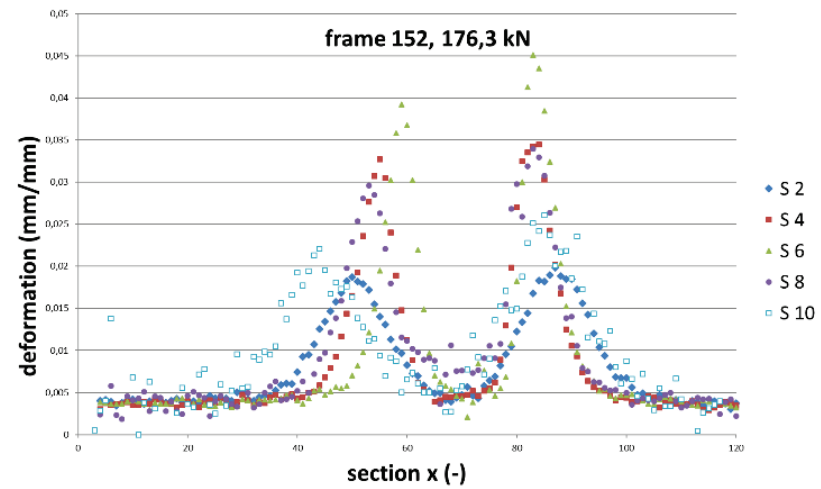

Figure 7 Sample frame measurements of deformations based on stereo-optical system

Based on sensitivity of optical methods one can conclude that these methods are suitable for measurements at larger loads, where signal to noise ratio is considerable for realistic measurements. In this particular case, where correlation between two methods is investigated and compared with finite element method results, we can conclude that the method is useful to follow crack growth at the opposite side of the material.

\section{NUMERICAL MODELLING AND SIMULATION}

Based on fracture graphic evaluation of the cross section of the specimen a semi-elliptical crack was defined in the model, as shown in Fig. 8.

The dimensions of strain gauges in the row for type HBM, model 1-KY21-2/120 [10] were also taken into account.

The FEM model was then developed for the modelling tool ABAQUS Explicit 6.13 [11], based on the given dimensions and the obtained material properties. The model shown in Fig. 8 was developed in symmetrical form, 
since the tensile test was performed symmetrically. The overall model consists of:

- 49588 (type C3D8R) elements

- 2408871 (type C3D10) elements

- 1430589 (type C3D4)

- $\quad$ in total this is 2369544 elements.

Where:

- $\quad$ C3D8R $=8$-node linear brick, reduced integration with hourglass control,

- C3D10 = 10-node quadratic tetrahedron,

- $\quad$ C3D4 = 4-node linear tetrahedron.

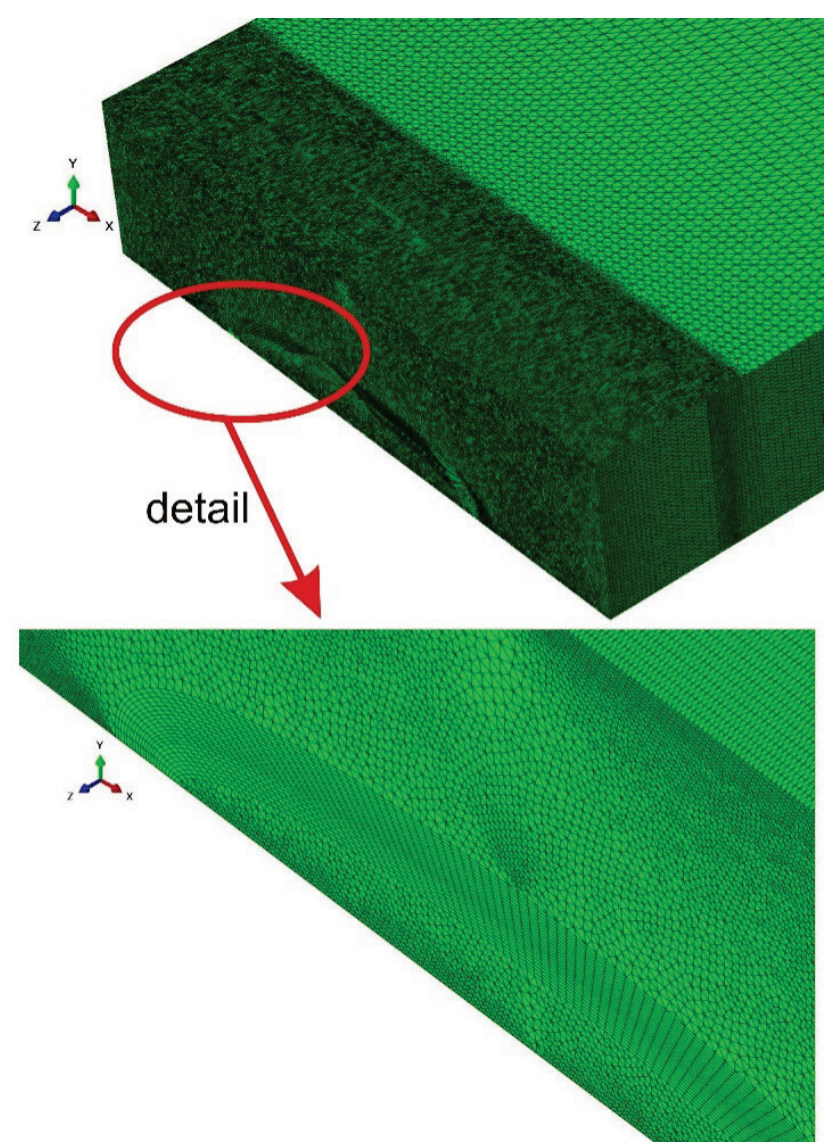

Figure 8 FEM model of specimen with semi-elliptical crack after tensile test

Based on the specific time frame of the loading during tensile test, which represents specific force at that time, four forces were determined and evaluated to represent results with different loadings $(F=11.7 \mathrm{kN}, 20.6 \mathrm{kN}, 50$ $\mathrm{kN}$ and $73.8 \mathrm{kN}$ ) in order to follow loading characteristic given in Fig. 2.b).

The numerical results of specimens are shown in Fig. 9 at the load $F=73.8 \mathrm{kN}$. It is obvious that the highest stress concentration appeared along the semi-elliptical crack front. For comparison of different strain measurement techniques, the numerical calculated strain values in area of stress monitoring are necessary to be analysed and compared. The FEM numerical analyses were performed at three locations as shown in Fig. 9. FEM0 represents deformation results at the opposite side of the crack symmetrically to the crack location, FEM-1 represents results on the opposite side of the crack located $6.5 \mathrm{~mm}$ aside of the crack axle, and FEM-2 represents deformations on the same side of the crack with $6.5 \mathrm{~mm}$ shift at the location of installed strain gauges.

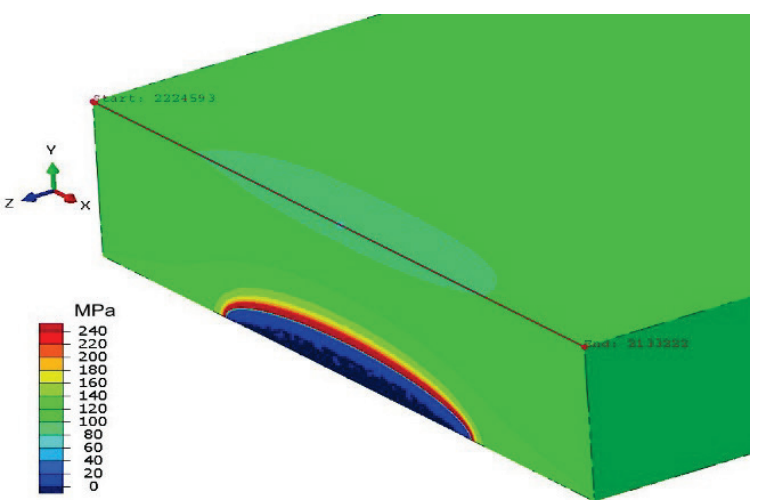

a) FEM-0; line above semi-elliptical crack

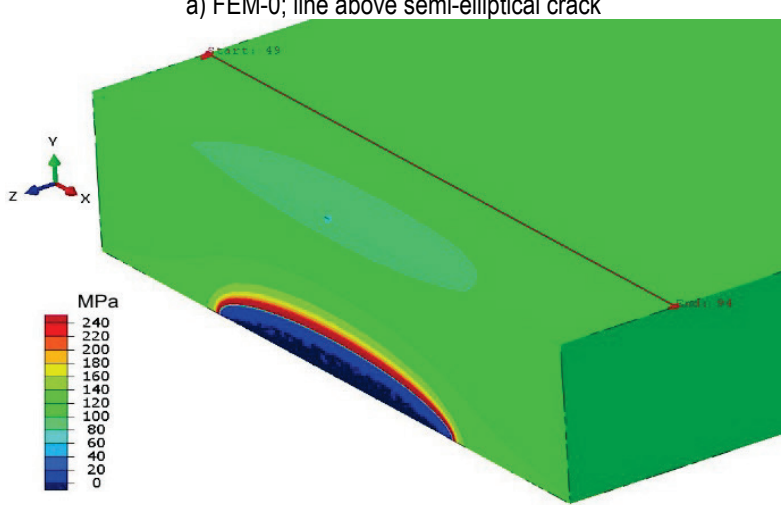

b) FEM-1; line above semi-elliptical crack and $6.5 \mathrm{~mm}$ left

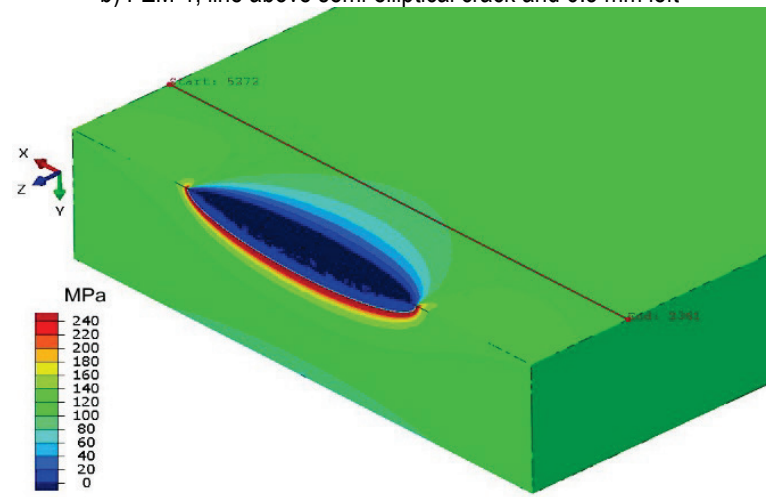

c) FEM-2; line near semi-elliptical crack and $6.5 \mathrm{~mm}$ left in location of Straingauges

Figure 9 FEM analyses for three locations (FEM-0, FEM-1, FEM-2)

The stress comparison between FEM-1 model results and Aramis results is shown in Fig. 10. The results are presented for two symmetrical sections $6.5 \mathrm{~mm}$ from the axis over the crack (sections 48 and 92), which are 22 pixels from centreline section 70 . The results are marked with the area in circles for a particular stress and loading value. Solid lines are FEM results and dots are Aramis results.

The comparison between stereo optical results and FEM-1 results presented in Fig. 10 shows reasonably good matching at the bulk of the specimen body with $5-10 \%$ difference. The noise at the edge of the specimen (dotted circle at the edge of specimen) is the reason for bad measured stress/deformation at the edge of the specimen with the Aramis. The noise at lower forces is one of the main drawbacks of Aramis method to be used for crack propagation monitoring via surface deformation measurements.

The comparison between FEM-0 results with Aramis is shown in Fig. 11. The symmetrical location is at section 
79 in the $x$ dimension, at the crack axis. The loading values are at the same time frames $(27,49,91$ and 129$)$.

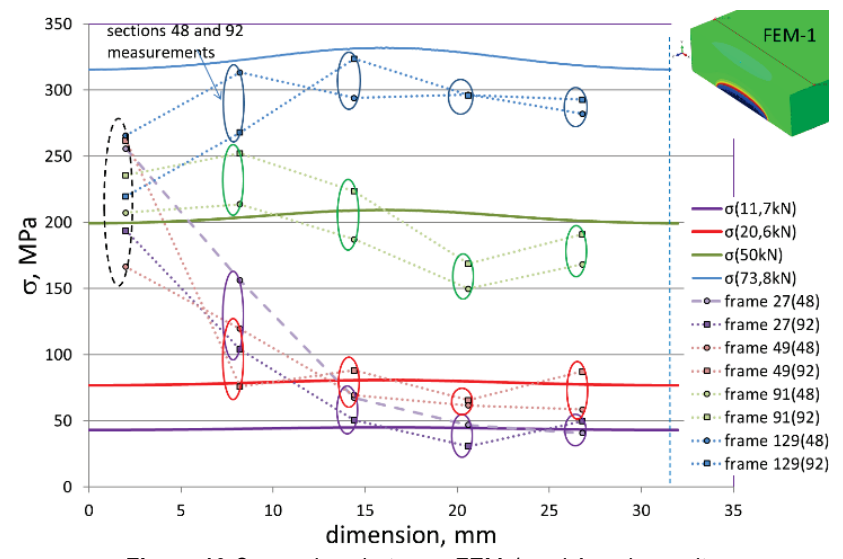

Figure 10 Comparison between FEM-1 and Aramis results

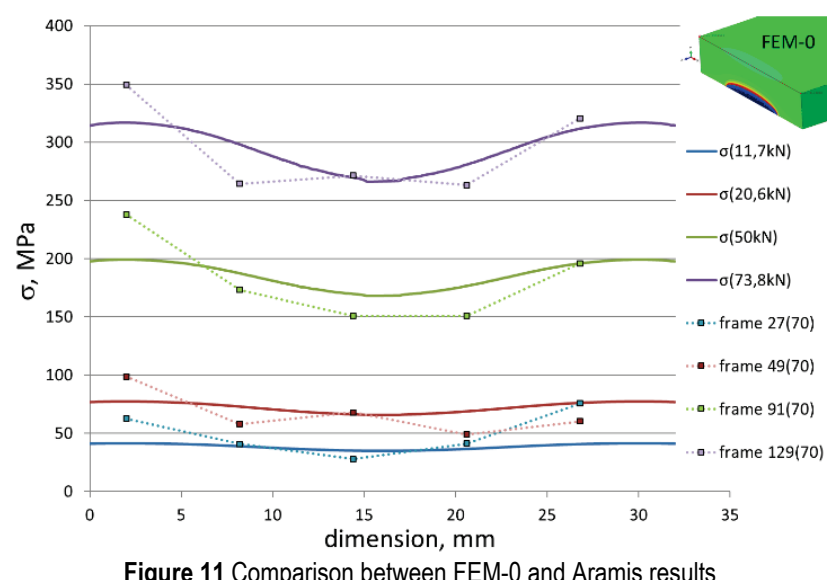

The results at the location on the symmetrical position on the other side of the crack are matching very well and appropriate trends are seen through the whole width of the specimen. The typical saddle in the mid area is due to lower stress at the middle section where the semi-elliptical crack was present. With the higher loads, the residual stress was increasing at the side of the material dimension, due to higher stress intensity factor at the edge of the material.

The third comparison is done for the results of FEM-2 and strain gauges measurement results (see Fig. 11). Channels marked with $\mathrm{CH} \# \#$ represent strain gauges located on the surface of the material near the crack. All channels in red crossed format are those that failed during long term cycling loading. Channel $\mathrm{CH} 11$ represents reference strain gauge sensor installed remotely from the crack as shown in Fig. 3.

The results at lower forces are comparable with the same range as the FEM-2 values and trends of the loading (see Fig. 7). At higher forces, the response values are decreasing. The reference sensor values $\mathrm{CH} 11$ are comparable with calculated FEM-2 values, but the other values are distorted, especially when forces become higher. During loading with cyclical force, the junction between strain gauges and material surface became deformed with some residual stresses. This is more relevant near the crack of the specimen and less when distant from the crack. However, the response trends are still present and could be used for crack propagation monitoring and evaluation.
Similar approach has been shown in article [12] by Kotšmid et al.

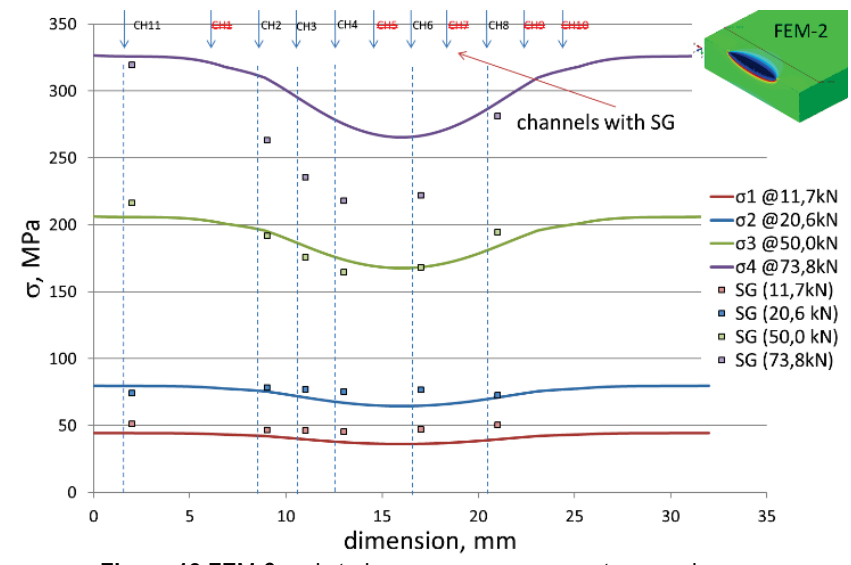

Figure 12 FEM-2 and strain gauges measurement comparison

\section{CONCLUSIONS}

The purpose of this paper is to present two correlated methods for deformation response on the surface of material and compare them with results from FEM methods. In this paper, the tensile test analyses of specimen with semi-elliptical crack are presented. The specimen semi-elliptical crack grew under cyclic fatigue loading. The tensile test performed monitored conditions at the surface side of the crack by strain gauge sensors, with GOM ARAMIS stereo-optical measurements [9] on the opposite site of the crack and with loading and deformation conditions based on the Instron servo-hydraulic testing device.

The results of three different methods were compared, deformation behaviour measured with strain gauges, deformations measured with optical method and results from FEM analyses. The applied methods were evaluated to determine their practical usefulness with limits and deficiencies from crack propagation measurements with deformation response evaluation.

Comparison with stereo-optical measurement system demonstrated good matching of all three methods of deformations determination in the linear-elastic region of loading. It was determined that strain gauge measurement gives good results at lower linear-elastic loadings, but at higher loadings near yield stress, results are not proportional any more.

Stereo-optical methods used for deformations measurements are sensitive at lower loadings because of noise, which contributes less at higher loadings, where results match well FEM analysis results at different surface locations. The methods developed for relaxation measurements with strain gauges and correlation measurements with stereo optical methods assure monitoring of fatigue crack propagation during operations based on the pre-determined calibration curve and allow us to detect crack growth in time and avoid sudden structural failure.

\section{REFERENCES}

[1] Chapetti, M. D. \& Jaureguizahar, L. (2012). Fatigue behavior prediction of welded joints by using an integrated 
fracture mechanics approach. International Journal of Fatigue, 43. 43-53. https://doi.org/10.1016/j.jfatigue.2012.02.004

[2] Jaureguizahar, L. \& Chapetti, M. D. (2009). Fatigue crack propagation analysis and characterization of surface in structural steel plates and welded joints. Proceedings of PACAM XI. https://doi.org/10.1007/s10659-008-9181-1

[3] Anderson, T. L. (1995). Fracture Mechanics - Fundamentals and Applications. CRC Press.

[4] Gubeljak, N. (2009). Mehanika Loma. Maribor: Založba Fakultete za strojništvo.

[5] Glaser, B., Gubeljak, N., Predan, J., \& Veg, A. (2015). Determination of Calibration Function for Fatigue Crack Propagation by Measurement Surface Deformation, ASTM International Selected technical papers, STP 1584, 113-131. https://doi.org/10.1520/STP158420140045

[6] Glaser, B., Gubeljak, N., \& Predan, J. (2015). Calibration Function for Fatigue Crack Propagation. Advances in Fracture and Damage Mechanics, 109-112. https://doi.org/10.4028/www.scientific.net/KEM.665.109

[7] Glaser, B., Gubeljak, N., \& Predan, J. (2017). Effect of the fatigue crack propagation on the strain measurements by stereoptical method and strain gauges. Fatigue and Fracture at all Scales, ICSID 2017, International Conference on Structural Integrity and Durability, Dubrovnik 2017. https://doi.org/10.1007/s00419-019-01531-2

[8] Glaser, B. (2018). Development of Method for Online Crack Growth Monitoring on the Surface of Material, Doctoral Dissertation, University of Maribor.

[9] ARAMIS - 3D Motion and Deformation Sensor. GOM GmbH. (2019, January 29). Retrieved from https://www.gom.com/metrology-systems/aramis.html.

[10] HBM Strain Gauges. (2019, January 29). Retrieved from https://www.hbm.com/en/0014/strain-gauges.

[11] CAE Abaqus software tools. Abaqus Unified FEA. (2019, January 29). Retrieved from https://www.3ds.com/productsservices/simulia/products/abaqus/.

[12] Kotšmid, S., Kuo, C., \& Beno, P. (2017). Buckling loads for steel tube with flattened ends. Archive of Applied Mechanics. ISSN: 0939-153. Volume 2017.

https://doi.org/10.1007/s00419-017-1224-2

\section{Contact information:}

\section{Bruno GLASER, M.Sc}

Nuklearna elektrarna Krško d o o.

Vrbina 12, 8270 Krško, Slovenia

bruno.glaser@nek.si

\section{Jožef PREDAN, prof. dr.}

University of Maribor,

Faculty of Mechanical Engineering,

Smetanova 17, 2000 Maribor, Slovenia

jozef.predan@um.si

Dražan KOZAK, prof. dr. sc.

University of Josip Juraj Strossmayer,

Mechanical Engineering Faculty in Slavonski Brod,

Trg Ivane-Brlić Mažuranić 2, 35000 Slavonski Brod, Croatia

drazan.kozak@sfsb.hr

Nenad GUBELJAK, prof. dr.

University of Maribor,

Faculty of Mechanical Engineering,

Smetanova 17, 2000 Maribor, Slovenia

nenad.gubeljak@um.si 